\title{
Chapter 3: Education and Social Self-Creation between Solid and Liquid Modernity
}

\author{
Jim Garris on $^{1}$ \\ ${ }^{1}$ Virginia Tech, Blacksburg, VA, USA \\ Correspondence: Jim Garrison, Virg inia Tech, 400B War Memorial Hall, Blacksburg, VA 24061, USA. E-mail: \\ wesley@vt.edu
}

Received: May 25, 2017

Accepted:September 1, 2017

Online Published: March 7, 2018

doi:10.5430/irhe.v3n 1p41

URL: https://doi.org/10.5430/irhe.v3n1p41

\begin{abstract}
This essay intersects John Dewey's pragmatism with Zygmunt Bauman's sociological thinking. It explores the creative dimension of Dewey's constructivism with an emphasis on social self-creation. Bauman's notions of solid and liquid modernity - among other things his ideas about conditions of time/space and work - supplement Deweyan constructivism by specifying some characteristics of the contemporary social environment that contribute to the social construction of the mind and self. The paper situates the Cologne International Teacher Education Laboratory within the flux of liquid modernity before discussing what Dewey's theory of inquiry may contribute toward teachers living a more enthusiastic, free, and more creative professional life. The paper concludes with a call for teachers and teacher educators to join with us in forming what Dewey would call a "public" of concerned, committed, and creative educators.
\end{abstract}

Keywords: Zygmunt Bauman, John Dewey, international teacher education laboratory, liquid modernity, self-creation, paradoxes of teaching

\section{Introduction}

As with the previous paper on "Constructivism, Inclusion, Democracy, and Education," my essay draws heavily on the insights of John Dewey's pragmatism in conjunction with Zygmunt Bauman's (2012) Liquid Modernity. Our paper emphasizes the creative dimension of Dewey's constructivism with special emphasis on self-creation in a social environment. The previous paper emphasizes the first two chapters of Bauman's book, "Emancipation" and "Individuality." My paper also explores emancipation by further extending those ideas while exploring individuality as social self-creation achieved through social inquiry in temporally and spatially distributed communities. However, I will place more emphasis on Bauman's chapters on "Time/Space," "Commun ity," and "Work," especially the work of teaching. I show that learning to teach in the Cologne International Teacher Education Laboratory (ITEL) - see chapter 2 - or in the Inclusive University School of Cologne - see chapter 1 - requires learning to cope through creative collaboration in a liminal space between both the conditions of solid modernity and liquid modernity without capitulating to dystopian influences of either one.

My first section identifies the remarkable compatibility of Bauman's liquid modern ity with Dewey's und erstanding of existence as comprised of events in constant flux. At first the resemblances seem so striking one suspects Dewey might endorse Bauman's depiction of liquid modern ity as morally desirable. However, Bauman hims elf suggests it is a "dystopia" and Dewey would agree (15). I will identify some of these dystopic aspects in the second section of our paper. The third locates the. The next two sections draw on Dewey to show how teachers may live enthusiastically, free, and creatively in liquid modernity by making good use of Dewey's theory of intelligent inquiry. Each of these sections contains connections to the ITEL as a lively community of inquiry. I conclude with a call to come jo in us while hoping you might ask us to join you in forming what Dewey would call a "public" of concerned, committed, and creative educators.

\section{Bauman's Liquid Modernity}

In the foreword to the 2012 edition, Bauman (2012) finds that what all forms of modern life have in common is "their fragility, temporariness, vulnerability, and inclination to constant change" (viii). All is flux without enduring identity: 
To 'be modern' means to modernize - compulsively, obsessively: not so much just 'to be', let alone to keep its identity intact, but forever 'becoming', avoiding completion, staying underdefined ... As time flows on, 'modernity' changes its forms in the manner of the legendary Proteus. ... [C]hange is the only permanence, and uncertainty the only certainty. (viii) (Note 1)

So-called postmodernity is simply a name for a phase within an endlessly morphing modernity.

Bauman recognizes that the conditions of solid and liquid modernity are "as a couple locked, inseparably, by a dialectical bond" (ix). "After all, he continues, "it was the quest for the solidity of things and states that most often triggered, kept in motion and guided their liquefaction" (ix). Modernity dissolved the solids of antiquity and the middle ages; liquid modernity is simply carry ing on the process of dissolving solids at a more rapid pace. Ba man does not seem to think anything is permanent while what "permits a distinction between the 'solid' and liquid' phases of modernity ... is the change in both the manifest and latent purposes" (ix). In Deweyan terms, Bauman makes a useful distinction, but does not allow it to decay into a sharp dualism.

In solid modernity, things simply moved more slowly. In time, "solids came to be viewed and accepted as transient" (ix). We may infer solid modernity by simple dialectical negation. Solid modernity is complete or completable, well-defined, forms are fixed and permanent, and identity immutable. Of course, in liquid modern ity "the relation of superiority/inferio rity between the values of durability and transience has reversed" (xii). In contrast to the quickness and agility of liquid modernity, solid modernity was slow and lumbering. Solid modernity could hope to complete the quest for certainty while liquid modernity refuses to even try.

Of course, Dewey famously rejected the quest for certainty, so epistemologically, it seems he should embrace liquid modernity (see LW 4). Likewise, his transactional realism also seems to provide a postmetaphysical agree ment. In a chapter whose very title suggests an intimate relation between liquidity and solidarity, "Existence as Precarious and as Stable," in his most metaphysical work Dewey affirms, "Man finds himself living in an aleatory world; his existence involves, to put it baldly, a gamble. The world is a scene of risk; it is uncertain, unstable, uncannily unstable" (LW 1: 43). Dewey's naturalistic metaphysics assumes that all we may ever hope to achieve is a "temporary equilibrium," wherein "A thing may endure secula seculorum and yet not be everlasting; it will cru mble before the gnawing tooth of time, as it exceeds a certain measure. Every existence is an event" (LW 1: 63).

Bauman is a sociologist describing the current socioeconomic, historical, and cultural scene while Dewey is a philosopher describing the very nature of existence. Dewey simply thinks existence always and everywhere is fluid; liquid modernity only obviates this fact. However, it is easy to also read Dewey as a philosopher of culture. "A feature of existence which is emphasized by cultural phenomena," Dewey proclaims, "is the precarious and pe rilous" (LW 1: 42). The cultural struggle continues, only the pace has accelerated. What has changed, according to Bau man (2012) is our attitude toward change: "Flexibility has replaced solidity as the ideal condition to be pursued of things and affairs. All solids ... are tolerated only in as far as they promise to remain easily and obediently fusible on demand" (ix). The new attitude embraces change for changes sake. Both Bauman and Dewey think it has gone too far in our affirmation of mere flux. We have lost our balance.

Bauman observes that culture must recognize the relatively stable and secure as well as the unsolidified for human beings to prosper. Dewey's naturalistic metaphysics identifies both as aspects of existence:

We live in a world which is an impressive and irresistible mixture of sufficiencies, tight completenesses, order, recurrences which make possible prediction and control, and singularities, a mbiguities, uncertain possibilities, processes going on to consequences as yet indeterminate. They are mixed not mechanically but vitally like the wheat and tares of the parable. We may recognize them separately but we cannot divide them, for unlike wheat and tares they grow from the same root. (LW 1: 47)

Notice that the mixture for Dewey is not dialectical, but vital; we may only separate them in thought. Even the most stable of things is in flux. It is only a matter of duration and rhythm of changes. Human individuals and cultures are likewise constantly evolving. For those that wish to live long and well, the task is always one of making the relatively stable prevail over the precarious while remaining open to further possibilities.

The following statement applies equally well to solid as liquid modernity, or any other age of humankind: "The striving to make stability of meaning prevail over the instability of events is the main task of intelligent human effort" (LW 1: 49). Because we live in a world where destructive change is constant, the task is one of intelligent, critical and creative construction, deconstruction, and reconstruction to avoid destruction.

Having examined the metaphysical and epistemological links between Dewey, Bauman, and liquid modernity, let us now turn directly to Bauman's sociocultural and political analysis. I start with his characterization, borrowed from 
Richard Sennett, of a prototypical personage of liquid modernity-Bill Gates. He "seems free of the obsession to hold on to things. His products are furious in coming forth and as rapid in disappearing" (Sennett cited in Bauman, 124). Instead, Gates preferred "positioning oneself in a network of possibilities rather than paraly zing oneself in one particular job" (124). Gates is boastful of his willingness to "destroy what he has made, given the demands of the immediate moment" (124) He delights in continuous creation, in this regard, I think Gates resembles Friedrich Nietzsche's Übermensch as a continuously creating and discarding values.

Bauman recognizes the existential implications of Gates'stance toward existence when he observes that along Gates' life-track "things were dumped as quickly as they were put together - and forgotten soon after" (124). Gates shares the Übermenschen's penchant for forgetting. He also shares the Übermenschen's talent for transvaluing the highest values; for instance, the ideal of immortality. Bauman depicts Gates as is suing "declaration of unconcern with eternal duration in favor of carpe diem" (124). Bauman continues:

Indifference to duration transforms immortality from an idea [i.e., ideal, value] into an experience and makes of it an object of immediate consumption: it is the way you live through-the-moment that makes that moment into an 'immortal experience'. If 'infin ity' survives the transmutation, it is only as a measure of the dep th of intensity of the Erlebnis ... . [I]f infinity, like time, is instantaneous, meant to be used on the spot and disposed of immediately, then 'more time' can add little to what the moment has already offered. (124-125)

In his Will to Power, Nietzsche writes: "What I relate is the history of the next two centuries. I describe what is coming, what can no longer come differently: the advent of nihilism (WP, Preface, sec 2). Liquid modernity is simply a phase of nihilis $\mathrm{m}$. Nihilis $\mathrm{m}$ is most commonly defined as the rejection of antecedently existing, eternal and immutable meanings, purposes, or values. Sometimes it implies life is entirely devoid of meaning. Here is how Nietzsche defines it: "What does Nihilism mean? That the highest values devalue themselves" (WP Book I, sec. 2). Like Nietzsche, Gates pursues the aesthetic solution to the problem of nihilism. The aesthetic solution is that we ourselves must create the meanings and values by which we live. Cologne social constructivism is one valuable way of understanding how we create meaning, and of critically analy zing the meanings we construct from multiple observer, participant, and agent perspectives.

Given the forgoing definition of nihilism, Dewey is a nihilist that shares Nietzsche's aesthetic solution to the problem of nihilism. For instance, there is no antecedently existing, eternal, and immutable meaning or purpose to education; so, instead, he offers a nonteleological ideal of endless growth: "[T] process of growth, having as its aim at every stage an added capacity of gro wth" (MW 9: 59). By gro wth Dewey means liv ing a life of expanding meaning and value wherein our ability to discern and creatively respond to the possibilities of existence continually develops. Perhaps Nietzsche agrees. Even if he does, there are important differences between Dewey and Nietzsche that matter a great deal, and which I will take up in my section on self-creation. One difference is that Nietzsche's Übermensch is a self-absorbed individual isolated from others and the community whereas for Dewey growth demands others and community participation. This difference is marked by Nietzsche's distaste for democracy. It matters immensely for those such as teachers and others in the caring professions that understand the meaning of their lives in creative self-transcending relation with others in the classroom and larger community.

However, Gates is Nietzsche's Übermensch with a twist. When, after thirty years as a hermit, the Übermensch first enters the market place he comes bringing gifts; he comes not to trade, but to "teach the overman" (Z Part I, sec. 1 and 2). Instead, he encounters "the most despicable man"; that is, "the last man," he "who lives the longest" (Z Part 1 , sec. 5). Zarathustra is made to suffer the folly of the last man: "We have invented happiness,' say the last men, and they blink" (Z Part 1, sec. 5). They do not wish to suffer the Übermensch's pains and struggles of creating genuinely new values. They want only happiness. Gates produces goods for consumption by the last men at the end of history as proclaimed by Francis Fukuyama (1992) at the end of the cold war wherein capitalism defeated communis m. Liquid modernity is the age of the last man who creates himself by consuming the goods of the market place. He has little interest in creating anything, and is especially disinterested in creating dramatically new values much less discerning between objects of immediate desire and those that would prove genuinely desirable in terms of human growth.

Gates and other entrepreneurs of liquid modernity are value creators only in the sense of market place values. He creates goods for consumption. The values he "creates" are as old as human trade. He only transvaluates along a pre-established value hierarchy wherein all values are commensurable, calculable, and exchangeable.

The market economy does not permit the construction of incommensurable values. Harvey Cox (1999) tells the following story: 
[I]n Great Britain when a railway pension fund that owned the small jeweled casket in which the remains of Saint Thomas a Becket are said to have rested decided to auction it off through Sotheby's. The casket dates from the twelfth century and is revered as both a sacred relic and a national treasure. The British Museum made an effort to buy it but lacked the funds, so the casket was sold to a Canadian. Only last-minute measures by the British government prevented removal of the casket from the United Kingdom. (5)

From the perspective of liquid modernity, governmental regulation rendered the casket far too solid and its value improperly incommensurable. Certainly, the market does not believe it is possible to devalue its highest values much less that they might devalue themselves. In liquid modernity, the market is God. If Cox is right, the Market will have no other Gods before it. Once upon a time, "The Market was never God, because there were other centers of value and meaning, other 'gods.' Market operated within a plethora of other institutions that restrained it." (3). Liquid modernity has melted all other values along with the institutions that defended them (including not only Govern ment, but also the Church) leaving only financial liquidity. Erlebnis confines itself to what can be created for sale by entrepreneurs and bought by consumers.

The story about the casket that perhaps contains the remains of Saint Thomas a Becket is hardly an amusing digression if we wish to comprehend liquid modernity. According to Bauman, understood in terms of sociopolitical and economic terms, the most distinctive cause of liquid modernity is "deregulation" (xiv). He then expands on what he means by it:

[T] he separation of power (that means, the ability to do things) from the politics (that means, the ability to decide which things are to be done) and the resulting absence of weakness of agency, or in other words the inadequacy of tools to the task; and also caused by polycentrism' of action on a planet integrated by a dense web of interdependencies (xiv)

Without some form of centralized power, particularly the power of the state after the demise of the church, there is nothing to tie things down and hold values in place in the new globalized world. Everyone and everything floats free from desperate immigrants to dilatant jet setters.

Most importantly, capital and capitalist may move readily wherever they will. Pierre Bourdieu shows how the very idea of capital has expanded to include not just economic, but cultural and social capital as well (see Reich 2013; Garrison/Neubert/Reich 2016, ch. 10). In liquid modernity knowledge becomes extremely important. Digitized knowledge and mobile modes of communication can connect anyone anywhere. National boarders no longer matter so much to the global capitalist, and woe to the nation that drives away capital by trying to regulate and tax it above tolerable levels. Capital flows like water seeking its own level. The most power and privilege goes to those that are the most knowledgeable nodes in the largest webs of capital in all its forms.

Although Bauman is a sociologist intent on describing what he finds, there are moments of normative intrusion. He observes "the unstoppably rising value of 'uprooted' people - migrants, refuges, exiles, asylum seekers: people on the move and without permanent abode "while citing evidence that they are an economic value in Europe" (xiv-xv). He also identifies the increasing income gap between the rich and the poor warning that "the prime victim of deepening inequality will be democracy" (xvii). Finally, there is planetary sustainability. Resonating with Cox (1999), Bauman writes:

[I]n the vernacular of the planet-wide congregation of the Church of Economic Growth the meaning of 'making life better', or just rendering it somewhat less unsatisfactory, means to 'consume more'. For the faithful of that fundamentalist church, all roads to redemption, salvation, divine and secular grace, and immed iate and eternal happiness alike, lead though shops. And the more tightly packed the shops' shelves waiting for the seekers of happiness to clear them out, the emptier is the earth. (xvii-xviii)

Here the good life is identified with the longings of the last man and growth means economic expansion not enlarging the scope of meaning and value.

In his 2012 Forward Bauman question asks: "Are those forms of life-in-common ... irrevocably things of the past" or will "chasing happiness through shops" prove "intrinsically and inevitably te mporary?" (xix). He seems to hope it is temporary: "The disintegration of the social network, the falling apart of effective agencies of collective action is often noted with a good deal of anxiety and bewailed as the unanticipated 'side effect' of the new lightness and flu idity of the increasingly mobile, slippery, shifty, evasive and fugitive power" (14). However, he remarks that it is a constitutive condition of liquid modernity that power flows free of any barriers or borders. Reflecting on the condition of liquid modernity, Bauman suggests people might become like electronic moles looking for sockets to occasionally plug into for power, although more likely in liquid modernity, disposable battery packs vended along 
the roadside of the information superhighway will replace sockets. He concludes with one of his few normative statements: "This seems to be a dystopia [sic.] made to the measure of liquid modernity"(15). I will take up some more of the dystopic components of liquid modernity in the next section. Here, I would like to suggest that Dewey's notion of "the public" in his The Public and Its Problems shows us how to form relatively stable (perhaps global) communities that allow us to prevail over the precariousness of liquid modernity without falling into illusions of permanence.

Bauman states: "Any true liberation calls today for more, not less, of the 'public sphere' and 'public power'”(51). What Bauman depicts in terms of the decay of the commons bears a striking resemblance to what Dewey calls, "The Eclipse of the Public" in The Public and Its Problems (LW 2). Dewey's book also poses a challenge by identifying how to establish and expand a public under conditions of liquid modernity. Dewey's depiction of the eclipse of the public under conditions of industrialism and solid modernity already anticipates the eclipse under conditions of post-industrialism and liquid modernity.

Dewey opens his chapter on "The Eclipse of the Public" by commenting that democratic optimis $m$ is on the wane. It is even more so today nearly ninety years later. He further noted that "American democratic polity was developed out of genuine community life" in "small centres" that have now dis appeared (LW 2: 304). Both Bau man and Dewey recognize the age of such communities is past. Dewey a lready realized this passing was due to the "consequences of technology," which have been further enabled today by the Internet and other forms of communicative technology. However, what nostalgia Dewey may have had for such times is not shared by Bauman (2012) who warns that while it is natural under conditions of liquid modern ity to seek to preserve identity within a community, many communities tend to exclude otherness and difference (108 and elsewhere).

Writing at the acme of solid modernity, Dewey thought public opinions were manufactured and standardized. "Mass production is not confined to the factory," Dewey opines (LW 2: 307). Bauman (2012) makes much of media, celebrity, and public display even among politicians (108 and elsewhere). Dewey speaks of "a musements" as well as "bread and the circus" to divert attention from public matters (LW 2: 321). The same people that sell us our automobiles sell us our politicians. Dewey draws a conclusion similar to Bauman that "the whole apparatus of political activities is a kind of protective coloration to conceal the fact that big business rules the governmental roost in any case" (309). Un like Bauman, Dewey emphas izes the excessive role of "trained specialists who manage things," by which he means governmental bureaucrats and technocrats. The result is government for, but not by, the people. Still, as Bauman helps us see, with governmental deregulation, the power of these many of these technocrats are much abated while much of what remains of government is to secure the pre rogatives of the ruling global plutocrats and not the people at all. Democratic optimism is, indeed, on the wane.

"The Great Society created by steam and electricity may be a society," Dewey declares, "but it is no community" (LW 2: 296). The Great Society in Dewey's day was the result of solid industrial forces, or what Bauman (2012) calls "Fordis m" (see 56-63 and elsewhere). However, as steam gave way to electricity, solid modernity melted. It is easy to generalize the following comment:

Our modern state-unity is due to the consequences of technology employed so as to facilitate the rapid and easy circulation of opinions and information, and so as to generate constant and intricate interaction far beyond the limits of face-to-face communities. Political and legal forms have only piecemeal and haltingly, with great lag, accommodated themselves to the industrial transformation. (LW 2: 306-307)

The unity of the global economy of liquid modernity is built out of commun icative technologies, molten capital, and a mobile workforce while political and legal forms not only lag even further behind, but political control is constantly deregulated as legal forms are rewritten for the privileged few while the commons, the public sphere, continues to shrink.

Dewey thinks there are many publics. Given his pluralis $\mathrm{m}$, he should have called his book "the Publics and Their Problems." This pluralism in how publics are formed. Human actions have consequences. Some of these consequences are largely confined only to those "directly engaged in a transaction" while some "affect others beyond those immediately concerned" (LW 2: 244). Roughly, this determines the difference between private and public transactions, although Dewey realizes it is only a useful distinction and not a hard division. Dewey understands "transaction" and consequence" in the sense of a flowing liquid:

If it be asked, "where" a transaction is located, the only possible answer, on the basis of legal procedure, appears in many cases to be that it is located wherever it has consequences which it is deemed socially important to regulate. (LW 1: 156) 
Whereas nothing is simply located in liquid modernity, Dewey thinks nothing has ever been simply located. Dewey defines the public this way: "The public consists of all those who are affected by the indirect consequences of transactions to such an extent that it is deemed necessary to have those consequences systematically cared for" (LW 2: 245-246). Meanwhile, "Officials are those who look out for and take care of the interests thus affected" (LW 2: 246). These officials, public intellectuals, agitators, leg is lators, judges, and such represent the people. When they fail to do so, the people may dismiss them. For Dewey, political sovereignty resides with the people not govern ment. Government exists to serve the needs of the various publics that demand government regulate consequences. He thought government, the state, was always secondary to the public. Dewey avers: "By its very nature, a state is something to be scrutinized, investigated, searched for. Almost as soon as its form is stabilized, it needs to be re-made" (LW 2: 255). For Dewey, both the state and publics should be only relatively stable. Liquid modernity arises as much from the inability of publics to find themselves and demand regulation in their, relatively stable, interests as from deregulation itself.

In liquid modernity, individuals are fragmented, ambivalent, and often unable to even identify their genuine self-interests much less others that share them. While perhaps not as serious, the problem of how distracted and confused people can form a public was already evident in the mid-twenties of the last century. "By what means," Dewey wonders, "shall its inchoate and amorphous estate be organized into effective political action relevant to present social needs and opportunities?" (LW 2: 313). Dewey's answer is by communication.

Till the Great Society is converted into a Great Community, the Public will remain in eclipse. Communication can alone create a great community. Our Babel is not one of tongues but of the signs and symbols without which shared experience is impossible. (LW 2: 324)

Dewey was committed to pluralistic communicative democracy. Taken from the standpoint of the individual, the Great Community "consists in having a responsible share according to capacity in forming and directing the activities of the groups to which one belongs and in participating according to need in the values which the groups sustain. (LW 2: 327-328). Meanwhile, from the standpoint of the great community, "it demands liberation of the potentialities of members of a group in harmony with the interests and goods which are common" (LW 2: 328). The task is to educate individual minds not just individuals with minds such that all individuals may make their unique contributions to the democrat community wherever it occurs. It is the task of the International Teacher Educatio $n$ Laboratory to provide opportunities for having and reflecting on experiences of unique individuality in dialogues across differences.

\section{Dystopia under Conditions of Liquid Modernity}

According to Bauman (2012), what traditional dystopias share is a "foreboding of a tightly controlled world; of individual freedom not just reduced to a sham or naught, but keenly resented by people drilled to obey commands and to follow set routines; of a small elite holding in their hands all the stings" (53). It is a totalized and totalitarian system. In these dystopias, everything is designed, managed, supervised. Everything is ordered with "monotony, regularity, repetitiveness and predictability" and rules are perfectly obeyed. Everything has a purpose. Everything is regulated in a Fordist universe of modern society in its "'heavy', 'bulky', or 'immobile' and 'rooted', solid phase" (57). Power and authority is centralized; Foucault's panopticon of surveillance prevailed. Weber's instrumentalist rationality do minated. Everything was assumed solid, fixed, stable, and epistemologically certain; hence, predictable. Dystopia under conditions of liquid modernity is not at all like those Aldous Huxley and George Orwell imagined (53 and elsewhere).

In many ways, the conditions of liquid modernity are so opposed to those of a classical dystopia that they would seem to depict a utopia. Unlike with classical instrumentalism, the emphas is in the new logic of liquid modernity shifts from end to means: The new attitude is "We have found the solution. Now let us find a problem" (61). Liquid modernity is a world of flittering, uncertain, and unpredictable possibilities; carpe diem is the motto of the mo ment. Power and authority is distributed in the system; it is no longer centralized. We have moved from a "Panopticon-style to a Synoptican-style" wherein "the many watch the few" (85-86). "Spectacles take the place of surveillance" in liquid modernity (86). The "interview s ociety" and public media overthrow the Ro mantic concept of the self as poss essing "a deep hidden essence" concealed behind "external and superficial" (86). Genuine identity is understood as deeply ironic (87).

In liquid modernity, everything is turned inside out for display. We are only what we appear to be. Media celebrities expressing desirable lifestyle choices have replaced authorities. Even traditional authorities act increasingly more like celebrities. If centers of power emerge, they are transient and quickly disappear only to reappear briefly els ewhere. Indeed, the centers often appear as "personalities" in public media while celebrity can be fleeting. Politics 
is not a public affair any more; instead the "counsels which the counsellors supply refer to life-politics, not to Politics with a capital P" (65). We now have "life-coaches" and politics is no longer about the affairs of the polis. The public is more about the public discussion of private issues and lifestyles (69). Instead of the public sphere colonizing the private, the converse occurs in liquid modernity.

We have already seen how liquid modern ity dissolves the social nature of the self. Bauman reminds us of "Margaret Thatcher's infamous catchphrase: "There is no such thing as society" (64). The freedom of individuals to move about rapidly is critical for the new mobile g lobal workforce, so close social connections are considered corrosive to social coordination, which makes it hard for publics to find themselves. Everyone is alone in Nietzsche's war of all against all with all wherein every sources of social support is eroding and soon to dis appear.

Under conditions of liquid modernity, rationality is much less public and instrumental and much more private and calculative. Above all, regulation of individuals and society is limited to the minimum necessary for investors to calculate market risk and consumers their utilities. Free choice is imperative in a consumerist society. Indeed, everything comes down to individual autonomy upon which all success as well as failure reside. However, choice is confined to market choice, which makes a mockery of personalidentity construction.

Bauman (2012) recognizes the imperatives of identity creation, which are to make the relatively stable prevail over the precarious:

That work of art which we want to mould out of the friable stuff of life called 'identity'. Whenever we speak of identity, there is at the back of our minds a faint image of harmony, logic, consistency: all those things which the flow of our experience seems - to our perpetual despair - so grossly and abominably to lack. The search for identity is the ongoing struggle to arrest or slow down the flow, to solid ify the fluid, to give form to the formless. (82)

Securing unity of identity is equally important to Dewey, although he, like Bauman, realizes it is only ever relatively stable in a precarious world.

In his essay, "The Unity of the Hu man Being," Dewey depicts a unity not only of the mind and body, but also of the full unity of the human being as in a unified transaction with the environment:

We must observe and understand these internal processes and their interactions from the standpoint of their interaction with what is going on outside the skin - with that which is called the environment-if we are to obtain a genuine conception of the unity of the human being. (LW 13: 326)

His examples are respiration and digestion neither of which we can understand as simply located. For Dewey, transactions occur wherever they have consequences spatially and temporally.

Dewey approaches human identity concretely, not abstractly. Dewey finds "working together" in action provides "the clew to understanding the unity of the human being" (325). The cycle of life for Dewey involves an endless rhythm of need-demand-satisfaction of equilibrium-d isequilibrium-restoration of equilibrium of parts working together in the organism-environment transaction. The restoration of harmonious functioning establishes a form that completes a cycle of expansive growth:

Here in germ are balance and harmony attained through rhythm. Equilibrium comes about not mechanically and inertly but out of, and because of, tension. There is in nature, even below the level of life, something more than mere flu $\mathrm{x}$ and change. Form is arrived at whenever a stable, even though moving, equilibriu $\mathrm{m}$ is reached. (22)

Dewey states that the existence of rhythms in nature ... are the conditions of form in experience and hence of [aesthetic] expression" (167). He affirms the notion of unity in variety as essential to aesthetic form, but insists that "the unity in variety that characterizes a work of art is dynamic" (166). Dewey extends this aesthetic idea to include logical forms (see LW 12). The unity of the human being is a complex, distributed, trans actional phenomenon.

The notion of dynamic equilibriu m constitutes the unity of the human being physically, biologically, psychologically, and sociologically. Hence, it is not at all odd that Dewey would contend:

Is there anything in the whole business of politics, economics, morals, education, indeed in any profession, save the construction of a proper human environment that will serve by its very existence to produce sound and whole human beings, who in turn will maintain a sound and healthy human environ ment? (336)

Intelligently regulating the environment is the only possible way to achieve the unity of the self. That is why deregulation is so potentially disastrous. 
With the demise of all state regulation, we are thrown back upon the logic of the laissez-faire market. According the Bauman (2012), it is only by exalting God of the marketplace as our summum bonum may we form personal identity:

Given the intrinsic volatility and unfixity of all or most identities, it is the ability to 'shop around' in the supermarket of identities, the degree of genuine or putative consumer freedom to select one's road to the fulfillment of identity fantasies .... [T] [Te universal dependency on shaping - is the condition sine qua non of all individual freedom; above all of freedom to be different, to be to "have identity". (83-84)

In liquid modernity, self-creation requires consumption. Having more implies being more provided we also have the good taste to select the best brands and consume them like true connoisseurs in the right way at the right time. Bauman cites Jeremy Seabrook: "It is not so much that capitalism has delivered the goods to the people, as that the people have been increasingly delivered to the goods ... the selling of which alone gives shape and significance to our lives" (85). Ironically, the dystopic aspects of liquid modernity identified by Bauman reconstitute the atomistic individual of classical Enlightenment born with innate free will and rationality and rights understood reductively as meaning the right to shop uninhibited in a free market place where they may use their calculative rationality to get the most bang for the buck.

The deeper irony about identity in liquid modernity is that if everyone has exactly the same free will and everyone uses it exactly as they should, then everyone will do exactly the same thing in the same or similar situations. Differences arise only from calculative failu re or moral fallenness. The result is individuals with minds as Kricke and Neubert describe them (see chapter 2). Dewey depicts such minds thusly:

We do not know what we really want and we make no great effort to find out. We, too, allow our purposes and desires to be foisted upon us from without. We, too, are bored by doing what we want to do, because the want has no deep roots in our own judgment of values. There is a vicious circle. We yield to one kind of external pressure in doing what we like just as we yield to another kind in having to do what we don't like. The only difference is that pressure in the latter case is obvious and direct; in the former case it is subtle and indirect. (LW 5: 133)

The net result is a mockery of freedom and self-oppression. We are free to consume, but only a few are free to create and even then, like Bill Gates, they must create for market consumption. For the mu ltitude, creative self-expression is sacrificed as much as ever. I will investigate freedom in conjunction with creative inquiry later.

\section{International Teacher Education Laboratory: The Paradoxes of Teaching in Liquid Modernity}

It is easy to locate teaching within liquid modernity. Bauman (2012) borrows from Robert Reich's four broad categories, which form a "the power pyramid of light capitalism." The first category is that of "symbolic manipulator's" "who invent the ideas and the ways to make them desirable and marketable" (152). The second category is those engaged in "the reproduction of labour" and includes "educators or various functionaries of the welfare state" (152). Obviously, this category includes teachers. The third category involves those employed in "personal services" that involve face-to-face encounters with those that receive the services; it is comprised of those that sell, service, or produce the desire for products. Finally, there is the "routine labourers" that lack particular skills or interact with clients. They are disposable and, hence, have little interest in their work.

In contrast, to laborers, those at the top "love to create, play and be on the move" and live in a world of "volatile values" and are "carefree about the future the future, egotistical and hedonistic" (152). The number and quality of their social connections determine their value as a node in liquid modernity. They are "thriving on the uncertainty and instability of all things worldly" (154). Symbolic manipulators survive and thrive on their agility, connections, and being well informed so they may make the right moves.

While more secure than those below them, those actually engaged in classroom teaching are far less secure and certainly far less mobile that the symbolic manipulators who themselves must. One paradox of teaching in liquid modernity is that its practitioners largely participate in it under conditions of solid modern ity. K-12 teachers remain largely confined to the classroom where Foucault's panopticon of surveillance continues to prevail. Bauman opines:

People who move and act faster, who come nearest to the momentariness of movement, are now the people who rule. And it is the people who cannot move as quickly, and more conspicuously yet the category of people who cannot at will leave their place at all, who are ruled. Domination consists in one's own capacity to escape, to disengage, to 'be elsewhere', and the right to decide the speed with which all that is done - while simultaneously striping the people on the dominated side of their ability to arrest or constrain their moves or slow them down. (119-120) 
K-12 teaching is conspicuously in the category of those who cannot leave their place.

What is more, even within the building, teachers remain largely isolated from other adults for most of the workday. Furthermore, K-12 teaching remains massively regulated and, un like the practice of law or med icine, the regulations are almost entirely externally imposed by the state and often embedded in their own contexts of socialization and education. Referring to Michel Crozier, Bauman (2012) remarks, "people who manage to keep their own actions unbounded, norm-free and so unpredictable, while normatively regulating (routinizing and thereby rendering monotonous, repetitive and predictable) the actions of their protagonists, rule" (119). In many contemporary economies, teaching is a heavily regulated and standardized practice solidly confined in time and space.

There is a second paradox of teaching in liquid modernity, which is that teachers tend to personally reject the conditions of work in liquid modernity. For one thing, "bonds and partnerships tend to be viewed and treated as things meant to be consumed, not produced" (163). Good teachers never think of the student-teacher relationship this way. Indeed, they see teaching as a form of creative self-expression that produces many kinds of good for their students.

Liquid modernity is self-referring and ahistorical; it no long believes in collective work contributing progress as a public pursuit. There is no agency "able to "move the world forward'," nor is it "clear what the agency - any agency - should do to imp rove the shape of the world in the unlikely case that it is powerful enough to do it" (133 and 134). Teachers implicitly believe they have the agency to move the world forward and they know how to do it. Ba uman also argues that liquid modernity has abandoned hope in progress as collective social action. Instead, progress has become solely the work of individuals. Meanwhile, teaching is a self-transcending caring profession, which is why teachers are intrinsically committed to the future and most likely committed to progress, especially collective social progress expressed as social justice and equal opportunity. "Work has drifted from the universe of order-building and future-control," writes Bauman, "to the realm of a game" where what counts is "the immediate effects of every move: the effects must be fit to be consumed on the spot" (138). While no doubt it is sometimes useful to think of teaching as a game, teachers are profoundly committed to further control and order-building, nor do they expect to consume the good of their teaching moves on the spot. Bauman's claim that progress has been "deregulated and privatized" is a double paradox for teachers (135).

Paradoxically, International Teacher Education Laboratory in many ways is a product of liquid modernity. Its international component depends on the Erasmus Programme (European Community Action Scheme for the Mobility of University Students ), which is the expression of the European Union's concerns for youth and education. The program allows students to move freely among European Universities with little regulation by state governments or additional fees. Besides, the idea of ITEL is also in accord with the UN-convention (2006) that has led to the implementation of inclusive systems of education internationally. The ITEL is devoted to educating inclusive teachers in an inclusive setting.

We may also think of the ITEL as a Deweyan public that has found itself and must continually respond to the challenges of reconstruction and further development. Hence, if Bauman and Dewey are right, a site of true liberation. In that regard, we may see it as a democratic institution concerned with freedom, equality, and the public good. More than that, it is a genuine face-to-face democratic community nurtured by creative communication. Here, in communion with supportive others that would also answer the call to teach, students may experience once again the social nature of the self. Potentially, it might even lead to coordinated collective social action. In the next section, I will explore ITEL as a site of critical-creative inquiry and in the section after that a site of social self-creation of ones teaching and personalidentity.

I contend that because of all the paradoxes that attend the education of teachers in the International Teacher Education Laboratory, it is a liminal space at the boundary between solid and liquid modernity. While not a utopia (etymologically from the ancient Greek "ou" means "not" in English while "topia" means "place"), it is a place between solid and liquid modernity where prospective teachers may explore the world of teaching along with the larger world in comparative security, which allows intelligent risk taking and creativity. Liminal spaces are ideal for creating meaning by drawing on the best of what exists on either side of the threshold. Experiencing the diverse challenges and tasks of what it means to be a teacher in the ITEL could fall victim to the worst of two dystopias or create a fine working world from the best of each without attempting to escape the practical context of action by assuming some original utopia.

Bauman (2012) suggests that in such times at ours "the trick is to be a home in many homes, but to be in each inside and outside at the same time, to co mb ine intimacy with the critical look of an outsider, involvement with detachment" (207). I will try to show that the liminality of the ITEL allows those that live in that community to reside within and 
without its confines critically and creatively. It is a relatively secure home among the many homes prospective teachers have and will find as their career unfolds. Indeed, teaching is likely to remain a liminal activity caught between solid and liquid modernity for quite a long time. The ITEL prepares teachers to work agilely inside and outside both conditions to secure the creative autonomy and connections to others they seek.

\section{Emancipation, Freedom, and Inquiry}

The preceding paper deals well with the themes of emancipation and freedom. Because I believe that the aim of the International Teacher Education Laboratory is a community of critical-creative inquiry, in this section I will approach emancipation and freedom as a product of intelligent inquiry dependent upon a commun ity of inquirers.

Dewey exp licitly rejects "metaphysical freedom of the will" (LW 14: 209). Instead, for him, "Intelligence is the key to freedom in act" (LW 14: 211). What we want "is possibilities open in the world not in the will, except as will or deliberate activity reflects the world" (LW 14: 214). It is deliberation that emancipates us by creatively transforming the world and, thereby, ourselves. Dewey rejects the notion of pure rationality and thought. Instead, for him, intelligence is embodied in thought, feeling, and action.

For Dewey, inquiry always occurs in a disrupted context of action and terminates once we are able to re-coordinate the situation and move about without difficulty. Fundamentally, there is no difference between trying to resolve a problematic plumbing problem and completing a mathematical proof. The disruption is an embodied experience where we feel the disruption when embodied habits of action fail us and we must re-inhabit our world. We cannot unify our action without coordinating our thoughts and feelings within a disrupted situation.

We must be careful not to confuse having a problematic situation with having a problem since "something presents itself as problematic before there is recognition of what the problem is" (LW 5: 249). That is why for Dewey, intuition precedes conception and goes deeper" (LW 5: 249). Should we fail to intuit a problematic situation correctly reflection and intelligent deliberation will almost surely fail. Feelings and attitudes along with habits formed by prior experience influence the accuracy of such intuitions. Good teaching requires developing good intuitions.

Dewey asserts early in Human Nature and Conduct that habits "are will" and they "constitute the self" (MW 14: 22). Insofar as they constitute the self, they are the basis for achieving the unity of the self: "The dynamic force of habit taken in connection with the continuity of habits with one another explains the unity of character and conduct, or speaking more concretely of motive and act, will and deed" (MW 14:33). We will see below that this unity is at best only an enduring dynamic equilibrium. Later still, while discussing social self-creation, we will see that even dynamic equilibrium is more an ideal worth striving for than ever an actuality.

There is an understandable tendency to consider habits as internal and subjective, but Dewey rejects sharp inner versus out, subjective versus objective, or even organism and environment dualis ms: "For will, as we have seen, means, in the concrete, habits; and habits incorporate an environ ment within themselves. They are adjustments of the environment, not merely to it" (MW 14: 38). He goes on to note that environments are plural. We live in a world of overlapping physical, organic, and social environments. Human action is not simply located; it distributes itself wherever it has consequences in a world without a within. As we have already found, there is a flowing liquid aspect to pragmatis $m$ that realizes that nothing is absolutely solid; in such a world, the existential tas $k$ is always to find creative ways for the relatively stable to prevail of the precarious least we leave the scene of action disappointed, or worse. Schools and classrooms are instance of such action reliant on the formation of wise habits of willing what is truly good for our students and ourselves.

Good teaching also requires developing good habits of action. Such automaticity facilitates good action without requiring much conscious thought much less reflection and inquiry. Dewey declares:

Concrete habits do all the perceiving, recognizing, imagining, recalling, judging, conceiving and reasoning that is done .... Yet habit does not, of itself, know, for it does not of itself stop to think, observe or reme mber. Neither does impulse of itself engage in reflection or contemplation. It just lets go. Habits by themselves are too organized, too insistent and determinate to need to indulge in inquiry or imagination. (MW 14: 124)

Deliberative inquiry requires we stop and think. We think when habits fail.

Dewey sharply distinguishes universalistic, utilitarian, calculative rationality from context of genuine deliberation calling for creative response and personal responsibility. Calcu lative rationality dominates liquid modernity where, if Bau man is right, it has replaced instrumental rationality. (Note 2) Calculative rationality assumes we may arrange all values in a predetermined hierarchy and then simply apply an already extant decision procedure. (Note 3) Accept of 
securing pleasure, or at least avoiding pain, the person making the decision remains, presumably, unaltered. Calculative rationality assumes a largely fixed and final self existing apart from action, including intelligent action. If this were true, the calculative decision process provides no opportunity for leaning and growth, except, perhaps, becoming a larger version of the present self. In contrast, Dewey asserts "the essential unity of the self and its acts" (LW 7: 288). For Dewey "the thing actually at stake in any serious deliberation is not a difference of quantity, but what kind of person one is to become, what sort of self is in the making, what kind of world is making" (MW 14: 150). Because we cannot seize upon antecedently existing forms of instant rationality, there is no choice but to bear moral responsibility for our decisions, including consumer choices (Note 4):

Now every ... choice sustains a double relation to the self. It reveals the existing self and it forms the future self ... Deliberation has an important function . . . because each different possibility ... presented to the imagination appeals to a different element in the constitution of the self. (LW 7: 286-287)

In a passage from The Public and Its Problems Dewey affirms: "Freedom or individuality, in short, is not an original possession or gift. It is something to be achieved, to be wrought out (LW 2: 62). We may readily extend the formation of self-identity here to include sociopolitical self-identity.

According to Dewey, genuine deliberation involves incommensurable values. Accordingly, "If values did not get in one another's way, if, that is, the realization of one desire were not incompatible with that of another, there would be no need of reflection " (LW 7: 210). Furthermore, Democracy and Education, Dewey asserts there is something "unique in an individual" and that no one is an individual "if there were not something incommensurable about him" (MW 9: 128). Given such a stance, it is not surprising that elsewhere Dewey explicitly states that "different wants are in themselves qualitative and incommensurable" (MW 15: 265). For Dewey, "Deliberation is a work of discovery. Conflict is acute. ... Deliberation is not an attempt to do away with this opposition of quality [by reducing it to commensurable quantities]. It is an attempt to uncover the conflict in its full scope and bearing" (MW 14: 150). The conflict is acute precisely because values are incommensurable and yet the agent must coordinate the situation. What we discover, or more accurately create, in deliberation is an end that will allow us to functionally coordinate our transactions. We will have much more to say about conflict and incommensurability below.

Such rationalism assumes value commensurability. For Dewey, a genuine indeterminate situation involves coordinating incommensurable values. As he sees it: “If values did not get in one another's way, if, that is, the realization of one desire were not inco mpatible with that of another, there would be no need of reflection" (LW 7: 210). In Democracy and Education, Dewey asserts there is something "unique in an individual" and that no one is an individual "if there were not something incommensurable about him" (MW 9: 128). Given such a stance, it is not surprising that elsewhere Dewey explicitly states that "different wants are in themselves qualitative and incommensurable" (MW 15:265). For Dewey, "Deliberation is a work of discovery. Conflict is acute ... De liberation is not an attempt to do away with this opposition of quality [by reducing it to commensurable quantities]. It is an attempt to uncover the conflict in its full scope and bearing" (MW 14: 150). The conflict is acute precisely because values are incommensurable and yet the agent must coordinate the situation. What we discover, or more accurately create, in deliberation is an end that will allow us to functionally coordinate our transactions; that is, to achieve the kind of unity discussed above.

Having rejected pure reason, Dewey argues that deliberation is an embodied and impassioned process. He defines deliberation as "dramatic rehearsal (in imagination) of various competing possible lines of action. It starts from the blocking of efficient overt action, due to that conflict of prior habit and newly released impulse to which reference has been made"(133). As opposed to cold reason, dramatic rehearsal allows us to vicariously experience in feeling and not just thought of the potential consequences of our actions. That is why novels, stories, stage plays, and the other arts also have so much to contribute to intelligent deliberation, which we must not confine to mere formal logic.

Emotions play an important part in Dewey's theory of deliberation. He declares: "The conclusion is not that the emotional, passionate phase of action can be or should be eliminated in behalf of a bloodless reason. More 'passions, not fewer, is the answer" (MW 14: 137). The idea is that only an emotion can properly balance an emotion so as to achieve dynamic equilibrium. For instance, to "check the influence of hate there must be sympathy, while to rationalize sympathy there are needed emotions of curiosity, caution, respect for the freedom of others" and more (MW 14: 137).

Deliberation for Dewey is creative; it involves creatively transforming the world so as to restore dynamic equilibriu $\mathrm{m}$ in our environ mental transactions (including the sociopolitical environ ment). Only imag ination allows us to perceive the possible in the actual and deliberate about actualizing it. Imag ination is also "the transferring of one 
experience over into another" (LW 17: 264). That is to say it is tropic dealing with metaphors, similes, synecdoches, and such. In dramatic rehearsal, we may transfer experience from the past and present into the future. We may also transfer the experience of others into our own. (Note 5)

Bauman (2012) remarks that 'the 'disembodiment' of ... human labour ... serves as the principle source of nourishment ... of contemporary capital" (120). Especially symbolic manipulators, but also educators in the top two rungs of the hierarchy of labor in liquid modernity are tempted to understand their work as entirely "mental," and assuming a mind versus body dualism, a matter of pure thought. Liquid modernity resembles antiquity, the middle ages, and enlightenment modernity, and solid (i.e., industrial) modern ity in perpetuating this dualis m. Dewey argues it is also a social class dualism, which has endured over the millennia as an abstract theory versus concrete practice dualism:

The actual conditions of life in Greece ... set up a sharp division between doing and knowing, which was generalized into a complete separation of theory and "practice." It reflected, at the time, the econ omic organization in which "useful" work was done for the most part by slaves, leaving free men relieved from labor and "free" on that account. That such a state of affairs is also pre-democratic is clear. (MW 12: 258)

These pre-democratic social class division remains to haunt teachers whose tasks many consider menial rather than free. The conditions of liquid modernity only acerbate the error. It remains a struggle for teachers who are caught between abstract theory and pure thought as "knowledge workers" that handle information yet are clearly practitioners of the art of teaching that involves students bodies, passions, and actions as well as their own. (Note 6)

There is one final component of Deweyan inquiry that defies the nonsocial, constructions of liquid modernity. For Dewey, "Logic is a social discipline" (LW 12: 26). He continues:

But man is naturally a being that lives in association with others in communities possessing language, and therefore enjoying a transmitted culture. Inquiry is a mode of activity that is socially conditioned and thathas cultural consequences. (26-27)

This means that every inquiry "grows out of a background of culture and takes effect in greater or less modification of the conditions out of which it arises" (LW 12:27). What is most at risk in any inquiry is not only the individual, but also the entire culture. The International Teacher Education Laboratory is a democratic community of inquiry. In his essay "Education as Politics," Dewey asserts that inquiry replace conventional idealizations schools will become "dangerous outposts of a humane civilization" (MW 13: 334). Because critical-creative inquiry can transform not only personal but also sociopolitical identity, ITEL is a subtly dangerous cultural outpost.

\section{Selfish vs. Social Self-Creation}

We have seen how Bauman documents the eclipse of the public and the social in liquid modernity. As a sociologist, he is extraordinarily insightful in this regard. As we have als o seen, Bauman (2012) is for the most part descriptive in his work, but when he does strike a normative note he expresses concern about the eclipse of the social and the role of the public and interactive public spaces. In his "Afterthought" in Liquid Modernity on writing sociology, he makes a remarkable connection between the poet's task and that of the sociologists. He bolds argues that true sociologists like true poets must challenge "pierce the walls of the obvious and self-evident, of that the ideological fashion of the day" (203). The task is to demolish such walls because "the walling-up of possibilities belies human potential while obstructing the disclosure of it bluff' (203). Thus described, the philosopher's task is the same as that of the poet and sociologist. Indeed, it is everyone's task in a democratic society. It is surely the task of the International Teacher Education Laboratory as a democratic learning community and environment. In this section, I will feature the ideal of social self-creation of good teachers.

Bauman argues that Niklas Luhmann's “most seminal and precious legacy to fellow sociologis ts had been the notion of autopoiesis-self creation" (203). In his The Creativity of Action, Hans Joas (1996) suggests that Dewey has the consummate theory of creativity; one that he argues surpasses that of Luhmann. Whether he is right or not, Dewey does have a hearty theory of creativity including a robust understanding of self-creation as social self-creation.

Dewey entirely rejected the enlightenment notion of the autonomous individual born with innate free will and rationality. As we saw in the essay by Kricke and Neubert (see chapter 2), even mere individuals with a mind are a sociocultural creation. Perhaps influenced by his colleague and good friend George Herbert Mead, Dewey advanced a very social understanding of the mind and self. For Dewey, 'Mind is ... a function of social interactions and ... a genuine character (LW 1: 6). Similarly, "Personality, selfhood ... are eventual functions that emerge with complexly organized interactions" (LW 1: 162). Ideally, the mind and self continue to emerge endlessly. That is why Dewey famously said: 
The aim of education is to enable individuals to continue their education ... [T] he object and reward of learning is continued capacity for growth. Now this idea cannot be applied to all the members of a society except where intercourse of man with man is mutual, and except where there is adequate provision for the reconstruction of social habits and institutions by means of wide stimulation arising from equitably distributed interests. And this means a democratic society. (MW 9: 107)

Dewey held a communicative theory of democracy.

Dewey is very clear that self-creation is social when, in his 1932 Ethics, he declares: "The kind of self which is formed through action which is faithful to relations with others will be a fuller and broader self than one which is cultivated in isolation from or in opposition to the purposes and needs of others" (LW 7: 302). For Dewey, we are constituted by our functional relations, especially social relations; hence, self-creation has a moral dimension to it.

Early in his career Dewey (1891) stated what he called "the Ethical Postulate":

In the realization of individuality there is found also the needed realization of some community of persons of which the individual is a member; and, conversely, the agent who duly satisfies the community in which he shares, by that same conduct satisfies himself. (EW 3:322)

Dewey remained dedicated to this hypothesis through all the many changes his philosophy underwent over the next 60 years. The postulate does not call for self-sacrifice to the larger community; he is a pluralistic democrat after all. The ethical postulate is simply a concession required to the contingent socially constructed character of human minds and selves.

We must not infer from the ethical postulate that Dewey is arguing for mindless social conformity, which would only yield individuals with minds. In a passage from The Public and Its Problems Dewey affirms: "Freedom or individuality, in short, is not an original possession or gift. It is something to be achieved, to be wrought out (LW 2: 62). Once achieved, we not only become social self-created beings, but being capable of re-creating the society that created us. "Our conduct is socially conditioned," Dewey asserts, the "effect of custom on habit and habit on thought is enough to prove this statement" (MW 14: 217). However, customdoes not necessarily determine human conduct:

Custom is Nomos, lord and king of all, of emotions, beliefs, opinions, thoughts as well as deeds. Yet mind in an individualized mode has occasionally some constructive operation. Every invention, every improvement in art, technological, military and political, has its genesis in the observation and ingenuity of a particular innovator. (LW 1: 164)

Democratic education seeks to educate unique individuals that may then make their unique contribution to culture. Indeed, there are functions a culture may come to find it requires only after the unique individual capable of performing it arrives on the scene.

Because we create each other transactionally, Dewey advocated pluralistic democracy - like in an inclusive classroom - as discussed by Kricke and Neubert above. As they indicate, such pluralistic multi-perspectivalis $m$ is critical to ITEL. Dewey holds that we live in a pluralistic universe in which diversity is essential to development: "There are at a given time unactualized potentialities in an individual because and in as far as there are in existence other things with which it has not as yet interacted" (LW 14: 109). Elsewhere, Dewey proclaims: "Potentiality thus implies not merely diversity, but a progressively increasing diversification of a specific thing in a particular direction" (MW 8: 11). Dewey thinks every individual has unique potential, but it is only possible to actualize it through transaction with otherness and difference.

Because the self is social, all self-creation is social self-creation. However, genuine growth, as opposed to perhaps becoming a larger version of the present self, involves transaction with other things, situations, and persons different from our selves. Indeed, Dewey is clear that his second, external, criteria of democracy implies "change in social habit" through exposure to other forms of life (MW9: 93). Diverse social transactions are essential to self-creation. In the encounter with others, we encounter ourselves.

We have seen that unity for Dewey unity is always tentative and transitive. Securing the temporary triumph of the relatively stable over the precarious is an endless struggle, and even when successful, the resulting unity is itself always precarious and conflicted:

He subconscious of a civilized adult reflects all the habits he has acquired; that is to say, all the organic modifications he has undergone. And in so far as these involve mal-coordinations, fixations and segregations (as they assuredly come to do in a very short time for those living in complex "artificial" conditions), sensory appreciation is confused, perverted and falsified . . . The actualization of meanings furnishes 
psycho-physical qualities with their ulterior significance and worth. But it also confuses and perverts them. The effects of this corruption are themselves embodied through habits in the psycho-physical, forming one-sided degraded and excessive susceptibilities; creating both disassociations and rigid fixations in the sensory register. (LW 1: 228-229) (Note 8)

From th is passage and others, Bruce Wilshire (1993) concludes that Dewey "thinks the 'soul of modern man' is a hellish mess" (267). While a perhaps a bit of an overstatement, passages from Dewey like the one above reminds us that for Dewey personal (or social) unity is at best a dynamic equilibrium:

Polarity, or opposition of energies, is everywhere necessary to the definition, the delimitation, that resolves an otherwise uniform mass and expanse into individual forms. At the same time the balanced distribution of opposite energies provides the measure or order which prevents variation from becoming a disordered heterogeneity. (LW 10: 161-162)

Dewey explicitly rejects totalitarian unity that includes not only unity in action but identity of belief in every phase of life, religious, moral, political, economic" (LW 17: 460). "This totalitarian ism," he continues, "was enforced by suppression of freedom of inquiry, speech, the press, and assemblage, even for religious purposes" (LW 17: 460). Dewey is a pluralistic, communicative, democrat. Whether it is with regard to cultural customs or the individual habits of the body, unity is always a fragile ever-changing state that involves constant struggle wherein the falling out of unity provides occasions for growth if we accept the risk and vulnerability while inquiring intelligently in community with others. The International Teacher Education Laboratory is one such Deweyan democratic community. I conclude with a call to come join us while hoping you might ask us to join you in forming what Dewey would call a "public" of concerned and committed educators.

\section{References}

Citations of the works of Dewey are to the critical edition. The Collected Works of John Dewey, 1882-1953, published by Southern Illinois University Press, Carbondale. Volume and page numbers follow the in itials of the series. For instance, MW 9: 1. Abbreviations for the volumes used are:

\section{MW The Middle Works (1899-1924)}

LW The Later Works (1925-1953)

Cox, H. (1999). The Market as God. Atlantic Monthly, 283(3), 18-23.

Drucker, P. F. (1959). The Landmarks of Tomorrow. New York: Harper and Row.

Drucker, P. F. (1999). Management Challenges for the 21 st Century. Harper Collins.

Garrison, J. (1995). Deweyan Prag matis m and the Epistemology of Contemporary Social Constructivism. American Educational Research Journal, 32(4), 710-740.

Garrison, J., Neubert, S., \& Reich, K. (2016). Democracy and Education Reconsidered - Dewey after One Hundred Years. New York: Routledge.

Lakoff, G., \& Johnson, M. (1999). Philosophy in the Flesh. New York, N. Y.: Basic Books.

Mousavi, S., \& Garrison, J. (2003). Toward a Transactional Theory of Decision Making: Creative Rationality as Functional Coordination in Context. Journal of Economic Methodology, 10(2), 131-156.

Nietzsche, Friedrich (1901/1967). Will To Power. New York: Vintage Books.

Reich, K. (2013). Chancengerechtigkeit und Kapitalformen. Wiesbaden: Springer.

Wilshire, B. (1993). Body-Mind and Subconsciousness: Tragedy in Dewey's Life and Work. In John J. Stuhr, (Ed.), Philosophy and the reconstruction of culture (pp.267-272). Albany: State University of New York Press.

\section{Notes}

Note 1. Nowhere in my paper has emphasis been added to any citation.

Note 2. We are about to see that Dewey's instrumental theory of deliberative inquiry is dramatically different from the kind of linear instrumentalism Weber ( $\mathrm{xxx}$ ) had in mind wherein we may divorce means from ends and proceed without much creativity or reflection. For De wey, means constitute the end; indeed, we have no means until we have secured the end (and conversely). We will see Dewey found inquiry necessarily creative in that it not only transforms the world, but the inquirer as well. 
Note 3. Here, I rely heavily on Mousaviand Garris on (2003)

Note 4. Of course, we are only hiding moral responsibility from ourselves when we mindlessly choose a culturally customary mode of resolution.

Note 5. So me of the most important work on metaphor in the last thirty-five years has is compatible with or directly involves Deweyan thinking. See Lakoff and Johnson (1999) for an extensive exposition of this work.

Note 6. The term orig inates with Peter Drucker (1957). Drucker (1999) later correctly prophesized that "the most valuable asset of a 21 st-century institution, whether business or non-business, will be its knowledge workers and their productivity" (135)

Note 7. Meanings acquired in connection with the use of tools and of language exercise a profound influence upon organic feelings. In the reckoning of this account, are included the changes effected by all the consequences of attitude and habit due to all the consequences of tools and language —in short, civilization. (xxx: 228-229) 